\title{
MEMLS3\&a: Microwave Emission Model of Layered Snowpacks adapted to include backscattering
}

\author{
M. Proksch ${ }^{1,5}$, C. Mätzler ${ }^{2,6}$, A. Wiesmann ${ }^{2}$, J. Lemmetyinen ${ }^{3}$, M. Schwank ${ }^{2,4}$, H. Löwe ${ }^{1}$, and M. Schneebeli ${ }^{1}$ \\ ${ }^{1}$ WSL Institute for Snow and Avalanche Research SLF, Flüelastrasse 11, 7260 Davos Dorf, Switzerland \\ ${ }^{2}$ GAMMA Remote Sensing Research and Consulting AG, Worbstrasse 225, 3073 Gümlingen, Switzerland \\ ${ }^{3}$ Arctic Research Center, Finnish Meteorological Institute FMI, 00101 Helsinki, Finland \\ ${ }^{4}$ Swiss Federal Institute for Forest, Snow and Landscape Research WSL, Zürcherstrasse 111, 8903 Birmensdorf, Switzerland \\ ${ }^{5}$ Institute of Meteorology and Geophysics, University of Innsbruck, Innrain 52, 6020 Innsbruck, Austria \\ ${ }^{6}$ Institute of Applied Physics, University of Bern, Sidlerstrasse 5, 3012 Bern, Switzerland \\ Correspondence to: M. Proksch (proksch@slf.ch)
}

Received: 19 December 2014 - Published in Geosci. Model Dev. Discuss.: 6 March 2015

Revised: 27 July 2015 - Accepted: 8 August 2015 - Published: 24 August 2015

\begin{abstract}
The Microwave Emission Model of Layered Snowpacks (MEMLS) was originally developed for microwave emissions of snowpacks in the frequency range $5-100 \mathrm{GHz}$. It is based on six-flux theory to describe radiative transfer in snow including absorption, multiple volume scattering, radiation trapping due to internal reflection and a combination of coherent and incoherent superposition of reflections between horizontal layer interfaces. Here we introduce MEMLS3\&a, an extension of MEMLS, which includes a backscatter model for active microwave remote sensing of snow. The reflectivity is decomposed into diffuse and specular components. Slight undulations of the snow surface are taken into account. The treatment of like- and cross-polarization is accomplished by an empirical splitting parameter $q$. MEMLS3\&a (as well as MEMLS) is set up in a way that snow input parameters can be derived by objective measurement methods which avoid fitting procedures of the scattering efficiency of snow, required by several other models. For the validation of the model we have used a combination of active and passive measurements from the NoSREx (Nordic Snow Radar Experiment) campaign in Sodankylä, Finland. We find a reasonable agreement between the measurements and simulations, subject to uncertainties in hitherto unmeasured input parameters of the backscatter model. The model is written in Matlab and the code is publicly available for download through the following website: http://www.iapmw.unibe.ch/research/ projects/snowtools/memls.html.
\end{abstract}

\section{Introduction}

Empirical observations reveal a wide range of different microwave signatures in active or passive remote sensing over snow covered areas as shown e.g., by Mätzler (1987). The lack of realistic models to understand these signatures was the motivation for efforts leading to the Microwave Emission Model of Layered Snowpacks (MEMLS) in the 1990s (Mätzler, 1996; Wiesmann and Mätzler, 1999). Initially the microwave emission behavior of single snow layers was investigated by Weise (1996) and later by Wiesmann (1997). The measurements led to an empirical approach for the scattering coefficient of snow in the frequency range $5-100 \mathrm{GHz}$ and correlation-length range $0.05-0.3 \mathrm{~mm}$ (Wiesmann et al., 1998) as well as to a first version of MEMLS (Wiesmann and Mätzler, 1999). Empirical relations for the scattering coefficient have also been implemented in the Helsinki University of Technology (HUT) model developed by Pulliainen et al. (1999) and later adapted by Lemmetyinen et al. (2010). MEMLS was extended to coarse-grained snow for correlation lengths up to $0.6 \mathrm{~mm}$ (Mätzler and Wiesmann, 1999). The snow microstructure was characterized by an exponential correlation function which allows computing the scattering coefficient analytically using the improved Born approximation (IBA) (Mätzler, 1998).

As an advantage of IBA and the characterization of snow in terms of correlation functions, the most relevant snow input parameters of MEMLS, correlation length and density, 
can be measured directly and objectively by various methods. Other models may require e.g., a conversion of measured parameters to model-effective ones (Kontu and Pulliainen, 2010; Lemmetyinen et al., 2015). The exponential correlation length could be e.g., obtained by micro-computed tomography ( $\mu$ CT) (Schneebeli and Sokratov, 2004) from a fit to the reconstructed three-dimensional microstructure (Löwe et al., 2013). Snow density and correlation length can be also obtained efficiently from field measurements (Proksch et al., 2015) using high-resolution penetrometry (SnowMicroPen SMP) (Schneebeli and Johnson, 1998). Alternatively, optical methods can be used, e.g., Matzl and Schneebeli (2006); Gallet et al. (2009); Arnaud et al. (2011), to measure the specific surface area (SSA) and use an empirical relation to compute the exponential correlation length (Mätzler, 2002). The latter method is appealing since SSA is commonly available. Accordingly, MEMLS was widely used for various questions related to passive microwave remote sensing (Durand et al., 2008; Rees et al., 2010; Toure et al., 2011; Langlois et al., 2012; Schwank et al., 2014).

In recent years, there was an increasing interest of the snow remote sensing community in active microwave measurements, which was mainly driven by the Cold Regions Hydrology High-Resolution Observatory $\mathrm{CoReH}_{2} \mathrm{O}$ (Rott et al., 2010) and related activities. However, single-layer models for the radar signal as presented in Rott et al. (2010) or Ulaby et al. (1984) are mainly used for efficient operation in retrieval schemes. For the sake of low complexity, these models are naturally based on strongly simplifying assumptions, e.g., treating snow as a collection of independent scatterers. However, scatterers are densely packed in snow and strongly interact with each other. More realistic models based on dense media radiative transfer (DMRT) have been developed (Tsang et al., 2007; Chang et al., 2014), including the possibility of using the numerical solution of Maxwell's equations for the single-layer scattering coefficients (Ding et al., 2010; Xu et al., 2012). The DMRT-based models however require at least two microstructural input parameters, which can be presently obtained only by $\mu \mathrm{CT}$ and often require time consuming casting procedures in the field.

To cope with recent requirements in active microwave remote sensing, while relying on an established, physical model of intermediate complexity, it is the aim of the present paper to extend MEMLS and develop a first version of MEMLS3\&a. Thereby, we can build on the description of the microstructure in terms of the exponential correlation length as a single, objective parameter which can be derived from in situ field measurements. For the backscattering model, we shall extend the description of the snowpack in MEMLS to account for a slightly undulated snow surface as shown in Fig. 1. The slightly undulated patches should be small enough to leave the emission largely unaffected but large enough to allow for specular backscattering at near-vertical incidence.

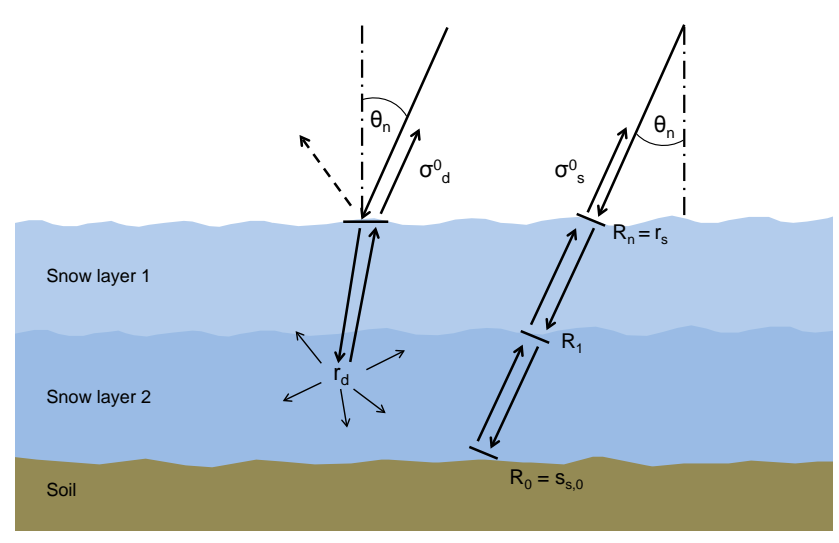

Figure 1. Snowpack (blue) with slightly undulated snow surface and layers. Waves incident at nadir angle $\theta_{n}$ are refracted at the snow surface followed by volume scattering with backscatter $\sigma_{\mathrm{d}}^{0}$ (left). Specular backscatter $\sigma_{\mathrm{s}}^{0}$ from a slightly tilted patch of the surface, soil and layer interfaces (right). Diffuse $r_{\mathrm{d}}$ and specular reflectivities $r_{\mathrm{s}}=R_{n}, R_{0}$ and $R_{1}$ are indicated.

The paper is organized as follows: in Sect. 2 we present the development of the model and the calculation of the total backscatter with its specular and diffuse components. In Sect. 3 the validation data consisting of active and passive microwave measurements from Sodankylä, Finland, are described. Section 4 presents the validation of both MEMLS and MEMLS3\&a using the Sodankylä data, followed by a discussion (Sect. 5) and the conclusions (Sect. 6). Details about the calculation of the specular reflectivity are given in the Appendix.

\section{Model development}

In MEMLS the snow cover is considered as a stack of $n$ horizontal layers with planar boundaries at the snow surface and between snow layers. Each layer is characterized by snow parameters (layer thickness, correlation length, density, liquid water content and temperature) that determine the layerradiative properties. Also the salinity can be taken into account layerwise. The snow-ground interface is characterized by a reflectivity $s_{0}$. A sandwich model is used to combine internal scattering and reflections at the interfaces. Internal volume scattering is accounted by a two-flux model (upand downwelling streams) derived from a six-flux approach (fluxes in all space directions). The absorption and scattering coefficients are functions of the six-flux parameters. The absorption coefficient can be obtained from density, frequency, temperature and salinity; the scattering coefficient depends on the correlation length, density and frequency. For a detailed description of MEMLS we refer to the technical documentation (Mätzler and Wiesmann, 2012). In the following, we focus on the backscatter model by considering the total backscatter as a sum of specular and diffuse components. 
Since the total reflectivity of a snowpack is related to its emissivity, it can be derived from passive observations alone. Thereby, active and passive observables can be appropriately combined to obtain a prediction for the radar backscatter.

\subsection{Link between active and passive observables}

At any given frequency and polarization of electromagnetic radiation with incident direction $\left(\mu_{n}, \phi_{n}\right)$ defined by zenith angle $\theta_{n}$ (where $\mu_{n}=\cos \theta_{n}$ ) and azimuth angle $\phi_{n}$ at the snow-air interface (cf. Fig. 1), the reflectivity $r$ of the surface is related to its emissivity $e$ (in the reciprocal direction) by Kirchhoff's law:

$r=1-e$.

For a more general description of Kirchhoff's law, see Mätzler and Melsheimer (2006). Equation (1) relates the emissivity, the key quantity of passive microwaves, to the reflectivity, a quantity linked to scattering. It is this relation that allows us to link active and passive microwave remote sensing. The reflectivity represents the fraction of the incident radiation that is scattered in the hemisphere above the surface. If the scattered radiation is diffuse (Lambertian reflectance) we can estimate the fraction in the backscatter direction. Furthermore, with information about the statistics of surface slopes, we can determine the contribution of backscatter arising from specular reflection at surface facets that are normal to the incident direction. Therefore, we will represent the total reflectivity as a sum of diffuse and specular components. The reflectivity can be represented as an integral over scattering directions in the upper hemisphere of the bistatic scattering function $S$ :

$r=\frac{1}{4 \pi \mu_{n}} \int_{2 \pi} S\left(\mu_{n}, \phi_{n}, \mu, \phi\right) \mathrm{d} \Omega=\frac{1}{2 \mu_{n}} \int_{0}^{1} S\left(\mu_{n}, \mu\right) \cdot \mathrm{d} \mu$

Here, $\mathrm{d} \Omega=\mathrm{d} \mu \mathrm{d} \phi$ is the infinitesimal solid-angle element in the scattered direction. The azimuth integration extends from 0 to $2 \pi$, and the last expression is valid for azimuthindependent functions. The function $S$ describes the scattering from incident direction $\left(\mu_{n}, \phi_{n}\right)$ to the scattering direction $(\mu, \phi)$. Thus, backscattering is determined by $S\left(\mu_{n}, \phi_{n}, \mu_{n}, \phi_{n}\right)$. Chandrasekhar (1960) introduced the $S$ function in his monograph on radiative transfer. He showed that $S$ is reciprocal:

$S\left(\mu_{n}, \phi_{n}, \mu, \phi\right)=S\left(\mu, \phi, \mu_{n}, \phi_{n}\right)$.

Furthermore, $S$ is identical to the bistatic scattering cross section $\sigma^{0}$ introduced by Ulaby et al. (1981), see their Eqs. (4.186) and (4.187), more exactly to the sum of the like- and cross-polarization terms, $S=\sigma_{\text {like }}^{0}\left(\theta_{n}, \phi_{n}, \theta, \phi\right)+$ $\sigma_{\text {cross }}^{0}\left(\theta_{n}, \phi_{n}, \theta, \phi\right)$. It is also related to Peake's (1959) function $\gamma=S / \mu_{n}$; i.e., the $1 / \mu_{n}$ factor of Eq. (2) is included inside this function. For completeness, we note that $S$ is related to but differs from other definitions: the reflection function $R$ used for instance by Kokhanovsky (2001) differs by a factor $\pi$ from the bidirectional reflection distribution function (BRDF) used in optical remote sensing (Kasten and Raschke, 1974), and all quantities are related by

$$
\begin{aligned}
S\left(\mu_{n}, \phi_{n}, \mu, \phi\right) & =\mu_{n} \gamma\left(\mu_{n}, \phi_{n}, \mu, \phi\right) \\
& =4 \mu_{n} \mu R\left(\mu_{n}, \phi_{n}, \mu, \phi\right) \\
& =4 \pi \mu_{n} \mu \operatorname{BRDF}\left(\mu_{n}, \phi_{n}, \mu, \phi\right) .
\end{aligned}
$$

The $S$ function can be highly complex. However, for diffuse scattering, some empirical functions are provided in the literature, see e.g., Mätzler and Rosenkranz (2007), the simplest one for Lambert scattering:

$S_{\mathrm{d}}=S_{0} \mu_{n} \mu$,

where the subscript d indicates diffuse scattering, and $S_{0}$ is a constant. By integration according to Eq. (2), we find that the diffuse reflectivity $r_{\mathrm{d}}$ is independent of the incidence angle, namely $r_{\mathrm{d}}=S_{0} / 4=R$, and thus equal to Kokhanovsky's $R$. The normalized backscattering cross section is given by $\sigma_{\mathrm{d}}^{0}=S_{\mathrm{d}}\left(\mu=\mu_{\mathrm{d}}\right)$, which can be expressed by $r_{\mathrm{d}}$ via

$\sigma_{\mathrm{d}}^{0}=4 r_{\mathrm{d}} \mu_{n}^{2}$.

Indeed, Lambertian behavior was found by the investigation of the HPACK model for snow by Mätzler (2000). It is an extension of an earlier one-layer, active-passive model of Tsang et al. (1982) to include multiple-isotropic scattering in the snow as well as refraction and reflection at the snow surface. The combined effect led to Lambert scattering for the diffuse component.

Unspecified in Eq. (6) is the separation of $\sigma_{\mathrm{d}}^{0}$ in its like- and cross-polarized components. For isotropic scatterers considered in HPACK, the first-order backscattering is like-polarized, and cross-polarization requires higher-order scattering. However, the structure of natural snow is highly complex, meaning that cross-polarization occurs for all scattering orders. Therefore, we introduce an empirical relationship with a splitting parameter $q$ which defines the crosspolarized part, whereas $(1-q)$ represents the like-polarized fraction, via

$\sigma_{\mathrm{d}, p p^{\prime}}^{0}= \begin{cases}(1-q) \sigma_{\mathrm{d}, \mathrm{v}}^{0}, & p=p^{\prime}=\mathrm{v} \\ (1-q) \sigma_{\mathrm{d}, \mathrm{h}}^{0}, & p=p^{\prime}=\mathrm{h} \\ q\left(\sigma_{\mathrm{d}, \mathrm{v}}^{0}+\sigma_{\mathrm{d}, \mathrm{h}}^{0}\right) / 2, & p=\mathrm{v}, p^{\prime}=\mathrm{h} \\ & \text { or } p=\mathrm{h}, p^{\prime}=\mathrm{v} .\end{cases}$

Here we took into account that $r_{\mathrm{d}}$ and thus $\sigma_{\mathrm{d}}^{0}$ are slightly different for horizontal $(\mathrm{h})$ and vertical (v) polarization (h- and v-pol). Now, Eq. (6) can be rewritten using the polarization terms for incident waves at vertical and horizontal polariza- 
tion, respectively:

$\sigma_{\mathrm{d}, \mathrm{v}}^{0}=\sigma_{\mathrm{d}, \mathrm{vv}}^{0}+\sigma_{\mathrm{d}, \mathrm{hv}}^{0}=4 r_{\mathrm{d}, \mathrm{v}} \mu_{n}^{2}$,

$\sigma_{\mathrm{d}, \mathrm{h}}^{0}=\sigma_{\mathrm{d}, \mathrm{hh}}^{0}+\sigma_{\mathrm{d}, \mathrm{vh}}^{0}=4 r_{\mathrm{d}, \mathrm{h}} \mu_{n}^{2}$.

An additional contribution to backscattering results from specular reflection as shown in Fig. 1. By considering only slight undulations, specular backscattering is limited to nearvertical incidence. For a Gaussian distribution of surface slopes, the backscattering coefficient of the specular term can be written as

$\sigma_{\mathrm{s}}^{0}=r_{\mathrm{s}, 0} \frac{\exp \left[-\tan ^{2} \theta_{n} /\left(2 m^{2}\right)\right]}{2 m^{2} \mu_{n}^{4}}$,

where $m^{2}$ is the mean-square slope, and $r_{\mathrm{s}, 0}$ refers to $r_{\mathrm{s}}$ at normal incidence (Fig. 1, right). This equation corresponds to the geometrical-optics solution for undulating surfaces, see Ulaby et al. (1982, Eqs. 12.45 and 12.46), and Kong (1986, Sect. 6.6). Here we generalize it from surface scattering to specular terms that fit the observation geometry (i.e., specular reflectivity for local normal incidence angle). Furthermore, we note that Eq. (9) describes like-polarized backscatter. For negligible anisotropy in the local surface plane the same values are obtained for hh (horizontal) and vv (vertical) polarization, and the cross-polarization terms are zero.

For both $\mathrm{v}$ and $\mathrm{h}$ polarization the total reflectivity is the sum of the diffuse and the specular component:

$r=r_{\mathrm{d}}+r_{\mathrm{s}}$.

While Eqs. (6) and (8) are valid for $r_{\mathrm{d}}$, Eq. (9) applies to $r_{\mathrm{s}}$ but taken at normal incidence. With some additional effort described below, MEMLS provides both $r_{\mathrm{d}}$ and $r_{\mathrm{s}}$ and the total backscattering coefficient as the sum:

$\sigma^{0}=\sigma_{\mathrm{d}}^{0}+\sigma_{\mathrm{s}}^{0}$

\subsection{Determination of $r$}

Apart from the physical temperatures of all snow layers including the ground temperature, the downwelling sky brightness temperature $T_{\text {sky }}$ must also be provided as input in MEMLS. The output is the brightness temperature $T_{\mathrm{b}}$ that is observed as upwelling radiation above the snowpack

$T_{\mathrm{b}}=r T_{\mathrm{sky}}+(1-r) T_{\mathrm{eff}}$.

Here $T_{\text {eff }}$ is the emission-effective temperature of snow and ground. The reflectivity $r$ can thus be computed via $T_{\mathrm{b}}\left(T_{\mathrm{b} 1}\right.$, $\left.T_{\mathrm{b} 2}\right)$ from two arbitrary and different values of $T_{\text {sky }}\left(T_{\text {sky1 }}\right.$, $T_{\text {sky2}}$ ), such as 100 and $0 \mathrm{~K}$. The reflectivity then follows from

$r=\frac{T_{\mathrm{b} 1}-T_{\mathrm{b} 2}}{T_{\mathrm{sky} 1}-T_{\mathrm{sky} 2}}$.

\subsection{Determination of $r_{\mathrm{s}}$}

According to Fig. 1 we need the specular reflectivities $r_{\mathrm{S}, \mathrm{V}}$ and $r_{\mathrm{s}, \mathrm{h}}$ at vertical and horizontal polarization at the observation incidence angle as well as $r_{\mathrm{s}, 0}$ at normal incidence. For brevity, we omit subscripts indicating the polarization and just write $r_{\mathrm{s}}$ instead of $r_{\mathrm{s}, \mathrm{v}}$ and $r_{\mathrm{s}, \mathrm{h}}$. In many situations $r_{\mathrm{s}}$ can be identified by the reflectivity of the snow surface. This is especially true for wet snow and for snowpacks that consist of a single layer. However, if an old snowpack is covered by fresh snow, the dominant specular layer may be the interface between the fresh and the old snow. Also, ice lenses form dominant reflectors inside the snowpack. Therefore, MEMLS requires a method that estimates incoherent specular reflectivities for arbitrary stratifications. This derivation is detailed in the Appendix. As a result, if all layer interfaces are assumed to be smooth and the corresponding interface reflectivities $s_{j}$ are determined by Fresnel's equations, the specular reflectivity $R_{j}$ resulting from layers below $z_{j}$ can be expressed in terms of a recurrence relation

$R_{j}=s_{j}+\frac{\left[\left(1-s_{j}\right) u_{j}\right]^{2} R_{j-1}}{1-u_{j}^{2} s_{j} R_{j-1}}, \quad j=1, \ldots, n$.

where $s_{j}$ is the interface reflectivity on top of layer $j$ and $u_{j}=\exp \left(-\gamma_{\mathrm{e}, j} d_{j} / \mu_{j-1}\right)$ is the coherent transmissivity of layer $j$ (Fig. 2). The extinction coefficient is denoted by $\gamma_{\mathrm{e}, j}$ and $d_{j}$ is the layer thickness. The specular reflectivity of the entire snowpack-ground system then is given by

$r_{\mathrm{s}}=R_{n}$

Equation (14) starts with $j=1$ at the ground as the lowest layer contributing to specular reflection. In contrast to the smooth interfaces assumed between snow layers, the ground is regarded as a rough surface and its reflectivity is additively decomposed into a diffuse and a specular part according to $s_{0}=s_{\mathrm{S}, 0}+s_{\mathrm{d}, 0}$. Accordingly, the ground reflectivity $R_{0}=s_{\mathrm{S}, 0}$ constitutes the initial condition for the recurrence relation (14).

\subsection{Synopsis of the backscatter model}

Finally, we briefly recap how specular and diffuse components from the previous section are practically reassembled in MEMLS3\&a for the computation of the total backscatter.

1. The total backscatter $\sigma^{0}$ is divided into a specular and diffuse component, $\sigma_{\mathrm{s}}^{0}$ and $\sigma_{\mathrm{d}}^{0}$, respectively (cf. Eq. 11).

2. The specular component $\sigma_{\mathrm{s}}^{0}$ is derived from Eq. (9) and arises from the rough soil surface (via $s_{\mathrm{s}, 0}$ ) and the layer interfaces and the snow-air interface, both of which are assumed to be slightly undulated.

3. The diffuse component of the backscatter $\sigma_{\mathrm{d}}^{0}$ is derived from the diffuse component $r_{\mathrm{d}}$ of the total reflectivity (Eq. 6), which requires the calculation of the total 


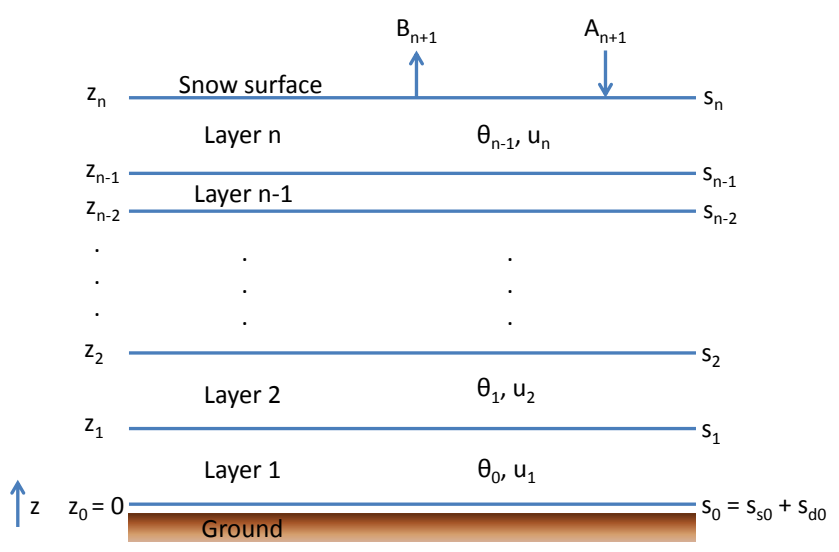

Figure 2. Geometry of the $n$-layered snowpack with up- and downwelling intensities $A$ and $B$. Height $z_{j}$, transmissivity $u_{j}$ of directed radiation, refracted angle $\theta_{j-1}$ and interface reflectivity $s_{j}$ for layer number $j$ ranging from 1 (bottom) to $n$ (top). Snow-ground reflectivity $s_{0}$, consisting of the specular $s_{\mathrm{S} 0}$ and diffuse component $s_{\mathrm{d} 0}$.

reflectivity $r$ (Eq. 13) and its specular component $r_{\mathrm{s}}$ (Eqs. 14, 15).

Thus, the model accounts for multiple scattering at the undulated layer interfaces. The diffuse scattered radiation is assumed to be Lambertian, which allows estimating the fraction scattered in the backscatter direction. More complex processes such as coherent backscatter enhancement recently presented by Tan et al. (2015) are currently not considered in MEMLS3\&a.

\subsection{Primary input parameters}

For a simulation run at a given frequency $f$, polarization $p$ and observation incidence angle $\theta_{n}$, all snow physical parameters described in Table 1 are required for each snow layer $(j=1,2, \ldots, n)$. From these primary input parameters, secondary parameters are computed as described in the previous version of MEMLS (Wiesmann and Mätzler, 1999).

\section{Validation data}

We used snow input data generated from three different snow measurement methods to run model simulations which are compared to backscatter measurements from ESA's SnowScat scatterometer for validation (Werner et al., 2010). All measurements were made on 1 March 2012 at the test site of the Finnish Meteorological Institute (FMI), in Sodankylä, Finland, during ESA's Nordic Snow and Radar Experiment (NoSREx) III (Lemmetyinen et al., 2013). The snow measurements were conducted directly in the field of view of the scatterometer and the radiometer in order to minimize the influence of the spatial variability of the snowpack.

\subsection{Test site}

In the NoSREx campaign, the SnowScat scatterometer and SodRad radiometers were installed on two platforms overlooking a forest clearing. For the NoSREx measurements, SnowScat was set to measure several incidence angles over a wide sector. For the purpose of the present work both SnowScat and SodRad were turned in azimuth to point towards the same location on the snowpack, where a destructive snow-pit measurement was made after the microwave measurements were completed.

The soil composition under the snowpack is dominantly mineral soil, with a thin vegetation layer on the surface (ca. $5 \mathrm{~cm}$ ). A survey conducted in 2010 resulted in a soil composition beneath the vegetation layer of $70 \%$ sand, $1 \%$ clay and $29 \%$ silt. Trees and shrubs higher than $10 \mathrm{~cm}$ were removed from the site prior to measurements. The surface vegetation consists of low lichen, moss and heather (Fig. 14).

\subsection{SnowScat}

The validation data were measured with ESA's SnowScat instrument (Werner et al., 2010) developed by Gamma remote sensing, Gümlingen, Switzerland. It is an X-to-Ku band, fully polarimetric step-frequency radar with an internal calibration loop which measures at a frequency range of 9.2$17.8 \mathrm{GHz}$, with a frequency resolution of $3.072 \mathrm{MHz}$. Data are presented for three sub-bands with center frequencies of $10.2,13.3$ and $16.7 \mathrm{GHz}$ with $2 \mathrm{GHz}$ bandwidth. The $-3 \mathrm{~dB}$ beam widths of the horn antennas are 5 and $12^{\circ}$, depending on frequency and polarization. An aluminum sphere is used as calibration target to correct for long-term drifts. The instrument is mounted on a $9 \mathrm{~m}$ high tower and is able to rotate in the azimuth direction and to vary the incidence angle. For the validation data used in this study, SnowScat was pointed directly at the location where the in situ measurements were conducted. The instrument was then operated at an incidence angle of $50^{\circ}$.

\subsection{SodRad}

The SodRad (Sodankylä Radiometer) system was mounted on a $4.1 \mathrm{~m}$ high platform. In 2012, measurements at 10.65 , 18.7, 21 and $37 \mathrm{GHz}$ (h- and v-pol) were available from the system. The radiometers were calibrated using a two-point calibration with external targets before the start of the campaign. Verification of calibration stability was performed using periodic observations of the sky at zenith. Absolute accuracy of the calibration was estimated to be better than $1 \mathrm{~K}$ for the 18.7, 21 and $36.5 \mathrm{GHz}$ channels, and better than $2 \mathrm{~K}$ for the $10.65 \mathrm{GHz}$ channel. The beam width of all channels was $6^{\circ}$. The fields of view of the radiometers were clear of all standing vegetation. 
Table 1. Primary input parameters used in MEMLS3\&a, with snow input parameters for each snow layer (upper part) and general model parameters (lower part). In addition, the value and unit of the parameter, as well as a typical way of determination, are indicated.

\begin{tabular}{|c|c|c|}
\hline Parameter & Value and unit & Determination \\
\hline density $\rho$ & {$[0-917] \mathrm{kg} \mathrm{m}^{-3}$} & traditional $^{\mathrm{a}}, \mathrm{SMP}, \mathrm{CT}$ \\
\hline exponential correlation length $l_{\mathrm{ex}}$ & $\mathrm{mm}$ & SMP, CT, (NIP) $)^{b}$ \\
\hline volume fraction of liquid water & {$[0-1]$} & traditional $^{\mathrm{a}}$, dielectric ${ }^{\mathrm{c}}$ \\
\hline snow salinity & {$[0-0.1] \mathrm{ppt}$} & electric conductivity \\
\hline layer thickness & $\mathrm{cm}$ & traditional $^{\mathrm{a}}$, SMP, NIP, CT \\
\hline temperature $T$ & $\mathrm{~K}$ & traditional $^{\mathrm{a}}$ \\
\hline physical ground temperature $T_{0}$ & $\mathrm{~K}$ & thermometer \\
\hline snow-ground reflectivity $s_{0}$ & {$[0-1]$} & modeled $^{\mathrm{d}}$ \\
\hline specular snow-ground reflectivity $s_{\mathrm{S} 0}$ & {$[0-1]$} & estimated from $s_{0} \mathrm{e}$ \\
\hline cross-polarization ratio $q$ & {$[0-1]$} & empirical \\
\hline mean slope of surface undulations $m$ & {$[0-\infty]$} & empirical \\
\hline
\end{tabular}

${ }^{\mathrm{a}}$ Fierz et al. (2009). ${ }^{\mathrm{b}}$ In combination with a density measurement (Eqs. 16, 17). ${ }^{\mathrm{c}}$ Denoth et al. (1984).

${ }^{d}$ Wegmüller and Mätzler (1999). ${ }^{\mathrm{d}}$ See text, Sect. 4.1.2.

\section{Validation results}

\subsection{Model initialization}

\subsubsection{Snow input parameters}

The most crucial snow input parameters required to drive MEMLS3\&a are density and correlation length. We derived these parameters from three different snow measurement methods in order to illustrate different ways of acquisition (Fig. 3). First, density and correlation length were derived according to Löwe et al. (2011), using three-dimensional reconstruction by $\mu \mathrm{CT}$ (Schneebeli and Sokratov, 2004) of snow samples cast in the field. The sample casting technique is described in detail by Heggli et al. (2009). Second, we used the SMP (Schneebeli and Johnson, 1998), a high resolution penetrometer. The derivation of density and correlation length from the SMP is detailed in Proksch et al. (2015). Finally, the near-infrared photography (NIP) developed by Matzl and Schneebeli (2006) allows measuring the specific surface area (SSA) of snow which is used to define the length scale:

$l_{\mathrm{c}}=\frac{4\left(1-\rho_{\text {snow }} / \rho_{\text {ice }}\right)}{\mathrm{SSA}}$.

The exponential correlation length $l_{\mathrm{ex}}$ is then obtained from the empirical relation,

$l_{\mathrm{ex}}=0.75 l_{\mathrm{c}}$,

put forward by Mätzler (2002).

As NIP does not provide the snow density, it was measured using a standard $100 \mathrm{~cm}^{3}$ density cutter with a vertical sampling interval of $4 \mathrm{~cm}$. A more detailed comparison of snow measurement methods with respect to microwave remote sensing can be found in Proksch and Schneebeli (2012). The density and correlation length profiles derived by the

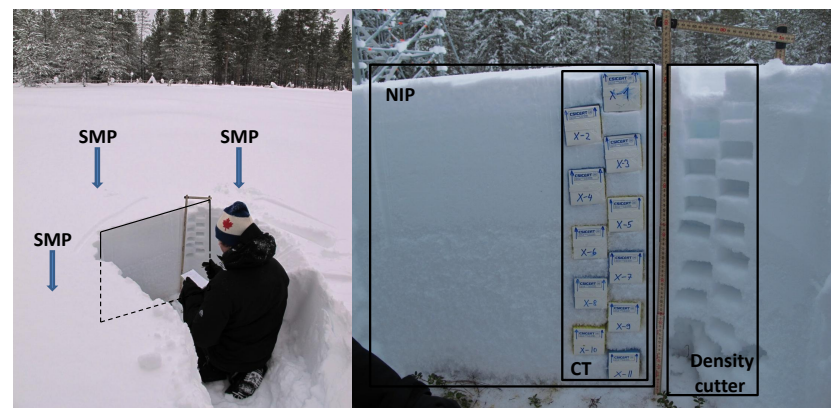

Figure 3. Left: snow-pit overview with the locations of the SnowMicroPen (SMP) measurements (arrows) surrounding the profile wall (black rectangular). Right: close-up of the profile wall, with locations of near infrared photography (NIP), computed tomography (CT) and density cutter measurements.

different methods are shown in Figs. 4 and 5. In general, the different methods are in agreement, besides the correlation length derived from NIP, which shows very large values in the lowest layer, an artifact of the preparation process of the profile wall. The snow temperature was assumed to be constant at $-3^{\circ} \mathrm{C}$. At this temperature the snow is dry and does not contain liquid water. The density and correlation length profiles were averaged to a vertical resolution of $3 \mathrm{~cm}$ to avoid any effects of coherent layers for the wavelength considered by SnowScat.

\subsubsection{Soil contribution}

Besides the snow input parameters, the snow-ground reflectivity $s_{0}$ is required. Since direct measurements were not possible due to the presence of the snow cover, this parameter has to be modeled. Here we used the empirical model of Wegmüller and Mätzler (1999), which was previously used in various studies (e.g., Lemmetyinen et al., 2010; 


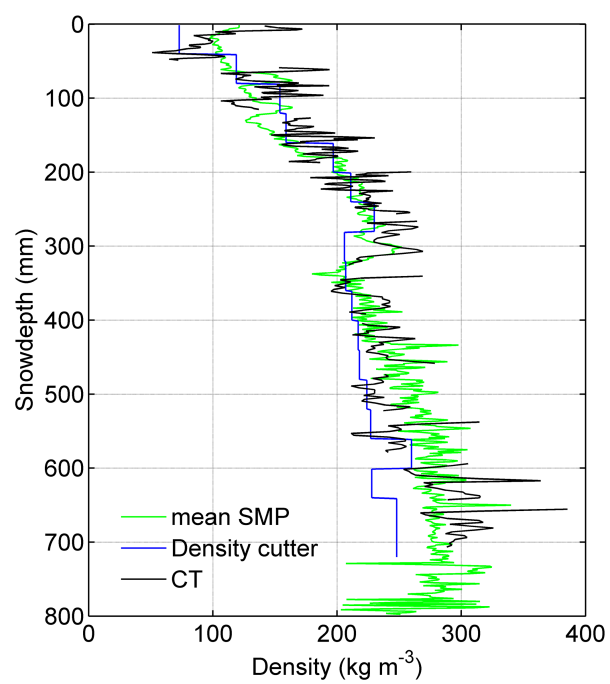

Figure 4. Density profile derived by SMP (green), $\mu \mathrm{CT}$ (black) and density cutter (blue). The green line is the average of three neighboring SMP measurements.

Takala et al., 2011; Rautiainen et al., 2012; Kontu et al., 2014). We used a value for the complex soil permittivity of frozen ground of $\epsilon_{\mathrm{g}}=3.6+0.9 i$, in line with Rautiainen et al. (2012), and set the standard deviation of the soil surface height $\mathrm{rms}_{\mathrm{g}}$ under the vegetation to $5 \mathrm{~mm}$.

To account for the correct incidence angle at the snowground interface, the following auxiliary procedure is carried out for each model run. First, MEMLS3\&a is run with $s_{0}=0$ and the incidence angle at the snow-ground interface is determined. Second, this angle was used in the model of Wegmüller and Mätzler (1999) to calculate $s_{0}$ which was then used to run MEMLS3\&a again, now accounting for the correct incidence angle on the snow-ground interface. The resulting values for $s_{0}$ ranged from 0.025 for $18 \mathrm{GHz}$ at v-pol to 0.037 for $10 \mathrm{GHz}$ at h-pol.

The model of Wegmüller and Mätzler (1999) gives the total reflectivity of the snow-ground interface. To determine its specular component $s_{\mathrm{s} 0}$, we assumed $s_{\mathrm{s} 0}$ to be proportional to $s_{0}$. A constant factor of $0.75\left(s_{\mathrm{s} 0}=0.75 s_{0}\right.$, for all polarizations and frequencies) was chosen to match SnowScat measurements with our simulations.

The soil temperature was measured to be $-2.5^{\circ} \mathrm{C}$. For the comparison to SnowScat observations, the cross-polarization fraction $q$ was chosen to match the microwave measurements, which led to $q=0.15$. The mean slope of surface undulations $m$ has no influence for an incidence angle of $50^{\circ}$ if values are smaller than 0.25 . We choose $m=0.1$ for our simulations. The sensitivity to both parameters will be discussed in Sect. 4.2.2.

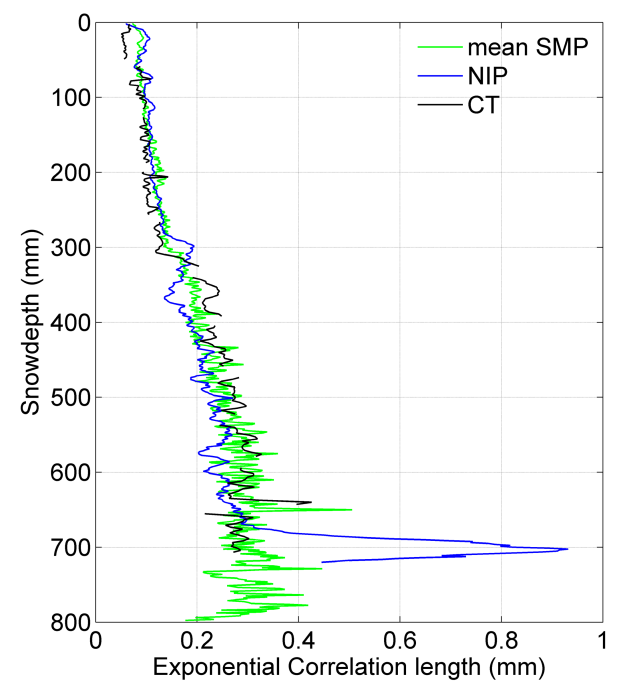

Figure 5. Correlation length profile derived by SMP (green), $\mu \mathrm{CT}$ (black) and NIP (blue). The blue line is the correlation length derived from the SSA measured by NIP according to Mätzler (2002).

\subsubsection{Sky temperature}

A further input to the model is the downwelling brightness temperature $T_{\text {sky }}$ of the sky. As SnowScat did not measure $T_{\text {sky }}$, we estimated $T_{\text {sky }}$ from the SodRad radiometer which measures the sky brightness temperature $T_{\mathrm{sky}, \mathrm{z}}$ at zenith. To fit our frequency interval of $10-18 \mathrm{GHz}$ used for the simulation, we linearly interpolated $T_{\text {sky,z }}$ values to match the interval. To convert $T_{\text {sky,z }}$ to an effective sky brightness temperature $T_{\text {sky }}$, which is representative for the whole scenery at the main test site, we first determined the sky opacity $\tau_{\mathrm{z}}$ at zenith from $T_{\text {sky,z }}$ (similar to Mätzler, 1994, their Eq. 7):

$\tau_{\mathrm{z}}=-\ln \left(\frac{T_{\mathrm{sky}, \mathrm{z}}-T_{\mathrm{air}}}{T_{\mathrm{back}}-T_{\mathrm{air}}}\right)$,

where $T_{\text {air }}=270 \mathrm{~K}$ is the air temperature and $T_{\text {back }}=2.7 \mathrm{~K}$ is the background radiation. A good approximation for the effective opacity $\left(\tau_{\text {eff }}\right)$ representative of the whole scenery is given by

$\tau_{\mathrm{eff}}=2 \tau_{\mathrm{z}}$,

as shown by Mätzler (2005). The sky brightness temperature is finally computed from

$T_{\text {sky }}=2.7 e^{-\tau_{\text {eff }}}+\left(1-e^{-\tau_{\text {eff }}}\right) T_{\text {air }}$.

\subsection{Results}

\subsubsection{Simulation results}

We choose the scattering option of the improved Born approximation (Mätzler, 1998) to run the model. For the soil, 


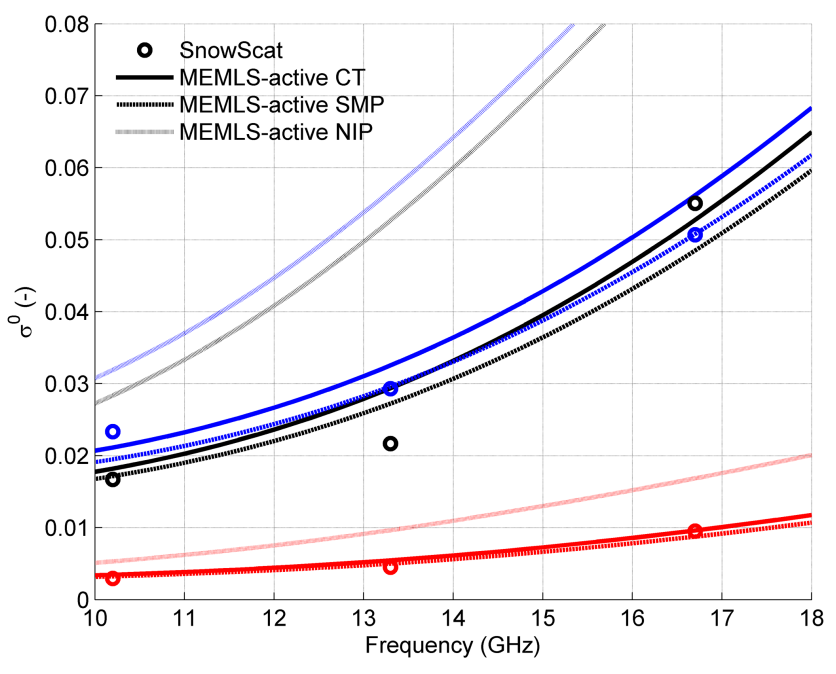

Figure 6. $\sigma^{0}$ measured by SnowScat (circles) and modeled by MEMLS3\&a (lines) with SMP (solid), CT (dashed) and NIP (dotted) inputs. MEMLS3\&a runs are performed with the snow-ground reflectivity $s_{0}$ calculated by Wegmüller and Mätzler (1999), and $s_{\mathrm{S} 0, \mathrm{~h}}=0.75 s_{0, \mathrm{~h}}, s_{\mathrm{S} 0, \mathrm{v}}=0.75 s_{0, \mathrm{v}}$. The mean slope of the surface undulation was set to $m=0.1$ and the cross-polarization ratio to $q=0.15$. Colors represent polarization, with vv - black, hh - blue and hv - red.

snow and $T_{\text {sky }}$ parameter settings described in Sect. 4.1, the results for MEMLS3\&a driven by SMP, CT and NIP input data are shown in Fig. 6 for an incidence angle of $50^{\circ}$. CT and SMP input results in good agreement between model and measurement, with mean absolute errors (MAEs) of $4.0 \times 10^{-3}$ and $4.3 \times 10^{-3}$ for vv polarization, $3.2 \times 10^{-3}$ and $1.6 \times 10^{-3}$ for hh polarization and $4.0 \times 10^{-4}$ and $5.3 \times 10^{-4}$ for hv polarization with CT and SMP inputs, respectively. NIP input leads to an overestimation of $\sigma_{0}$, which emerges from the NIP artefact towards the bottom of the profile (Sect. 4.1.1) where the correlation length values are too large. However, MEMLS3\&a driven with CT input data is in good agreement with SnowScat measurements (Fig. 7).

The dependence on the incidence angle at 10.2 and 16.7 GHz is shown in Figs. 8 and 9. MEMLS3\&a is in general agreement with SnowScat, with MEAs of $2.3 \times 10^{-3}$ and $9.6 \times 10^{-3}$ for vv polarization, $2.1 \times 10^{-3}$ and $1.2 \times 10^{-2}$ for hh polarization and $6.3 \times 10^{-4}$ and $2.6 \times 10^{-3}$ for hv polarization at 10.2 and $16.7 \mathrm{GHz}$, respectively. The polarization difference is slightly too small at $16.7 \mathrm{GHz}$. The SnowScat observations at different incidence angles show a certain amount of scatter, which we attribute to the heterogeneity of the ground and snow cover at the test site.

\subsubsection{Sensitivity analysis}

In this section, the sensitivity of MEMLS3\&a to $s_{\mathrm{s} 0}$ as well as to the two empirical parameters, the cross-polarization ratio $q$ and the root-mean-square slope of surface undula-

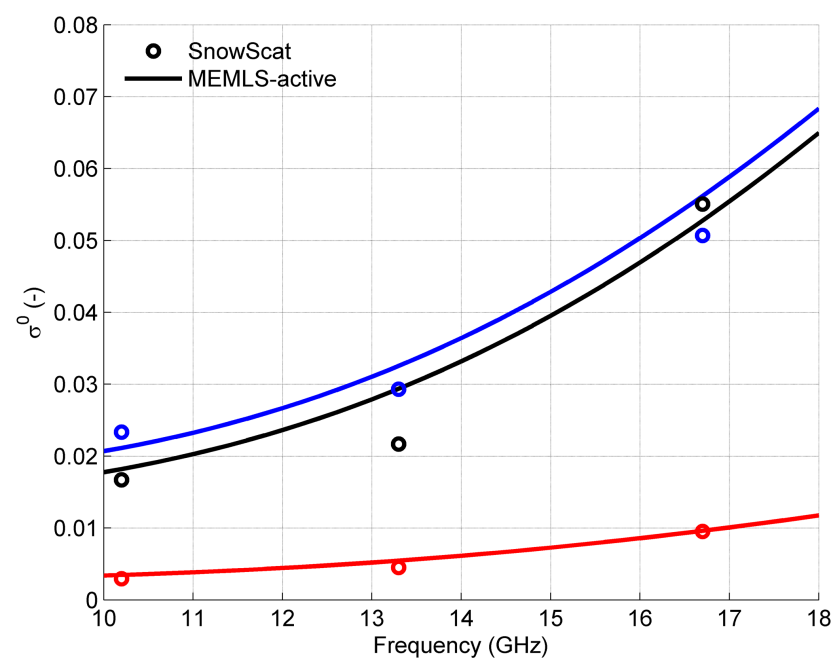

Figure 7. $\sigma^{0}$ at incidence angle $50^{\circ}$ measured by SnowScat (circles) and modeled by MEMLS3\&a with CT input (lines) for best fit parameters: $s_{\mathrm{S} 0, \mathrm{~h}}=0.75 \cdot s_{0, \mathrm{~h}} ; s_{\mathrm{S} 0, \mathrm{v}}=0.75 \cdot s_{0, \mathrm{v}} ; q=0.15$; and $m=0.1$. Colors represent polarization, with $\mathrm{vv}-$ black, $\mathrm{hh}-$ blue and hv - red.

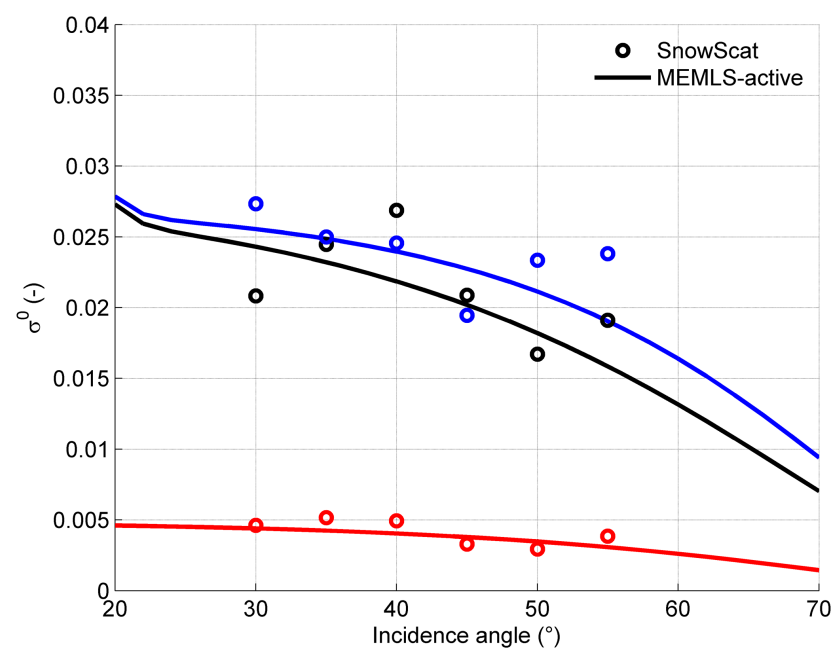

Figure 8. $\sigma^{0}$ at 10.2 GHz measured by SnowScat (circles) and modeled by MEMLS3\&a with CT input (lines). Colors represent polarization, with vv - black, hh - blue and hv - red. Best fit parameters according to Fig. 7.

tions $m$, are shown. For clarity, we restrict ourselves to those MEMLS3\&a runs which were driven with CT input data and the best fit values mentioned above $(q=0.15, m=0.1$, and $s_{\mathrm{s} 0}=0.75 s_{0}$ for both polarizations), if not indicated differently.

The specular snow-ground reflectivity $s_{\mathrm{s} 0}$ is a crucial parameter for the simulation because a higher specular snowground reflectivity leads to lower backscatter. This effect is larger at low frequencies due to the lower attenuation of electromagnetic radiation in snow. Figure 10 shows that $\sigma^{0}$ is 


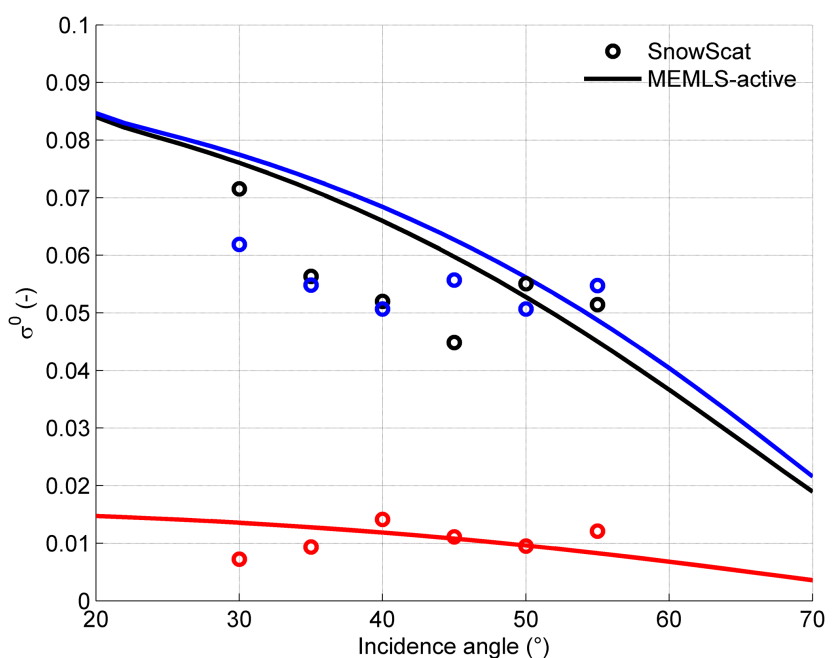

Figure 9. $\sigma^{0}$ at $16.7 \mathrm{GHz}$ measured by SnowScat (circles) and modeled by MEMLS3\&a with CT input (lines). Colors represent polarization, with vv - black, hh - blue and hv - red. Best fit parameters according to Fig. 7.

significantly increased with decreasing $s_{\mathrm{s} 0}$ values and vice versa, more pronounced at low frequencies.

The empirical cross-polarization ratio $q$ is the fraction of cross-polarized backscatter: increasing $q$ lowers copolarization and increases cross-polarization by the same magnitude (cf. Eq. 7). Figure 11 illustrates this by two values of $q$ (0.15 and 0.3 , respectively).

A larger value of $m$ represents a stronger undulated surface and increases the spectral component of the backscatter, in particular at small incidence angles. Figure 12 shows this behavior, with increasing backscatter for increasing values of $m$ and decreasing incidence angles. Given values smaller than $0.1, m$ has no effect at incidence angles larger than $25^{\circ}$. Furthermore, cross-polarization is in general not affected by $m$. Note that these results are only valid for the given snow and soil conditions, i.e., the sensitivity of parameters might change in different environmental conditions.

\subsubsection{Comparison with passive simulations}

To prove the concept of the MEMLS architecture, which is the fundament for MEMLS3\&a, we compare our active simulations with passive simulations using the same input data (Sect. 4.1). The validation data were measured by the SodRad radiometer (Sect. 4.1.3). Similar to SnowScat, SodRad was also pointed to the location of the in situ measurements (azimuth angle $140^{\circ}$ ). The instrument was operated at an incidence angle of $50^{\circ}$.

To run MEMLS, 15 SMP measurements inside the main test site in Sodankylä were used in order to capture the spatial variability of the snowpack. For each SMP measurement one MEMLS simulation was conducted. Figure 13 shows the

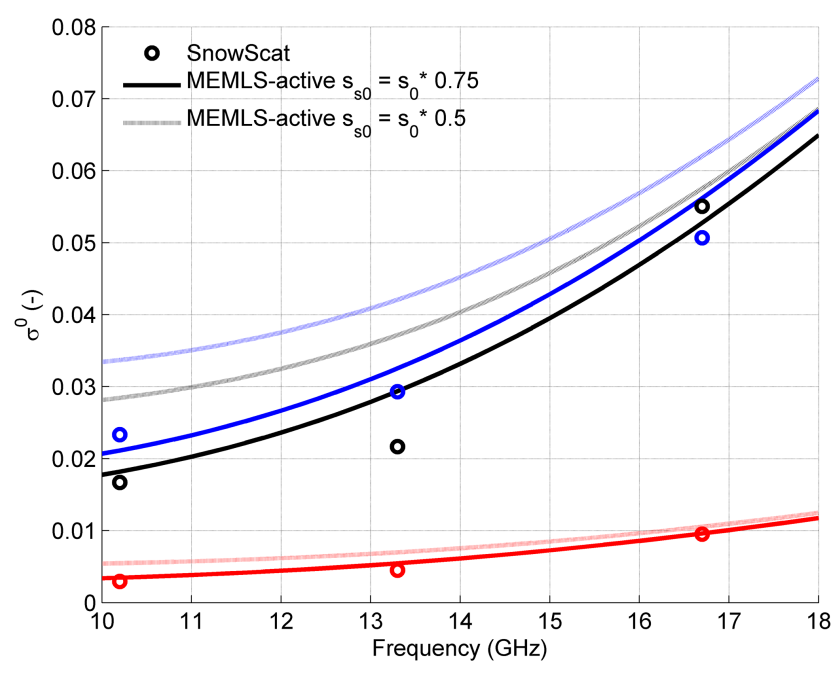

Figure 10. $\sigma^{0}$ at incidence angle $50^{\circ}$ measured by SnowScat (circles) and modeled by MEMLS3\&a with CT input (lines) for different specular snow-ground reflectivities $s_{\mathrm{S} 0}$. Higher $s_{\mathrm{S} 0}$ values lead to lower $\sigma^{0}$ values and vice versa. Colors represent polarization, with vv - black, hh - blue and hv - red. Best fit parameters according to Fig. 7.

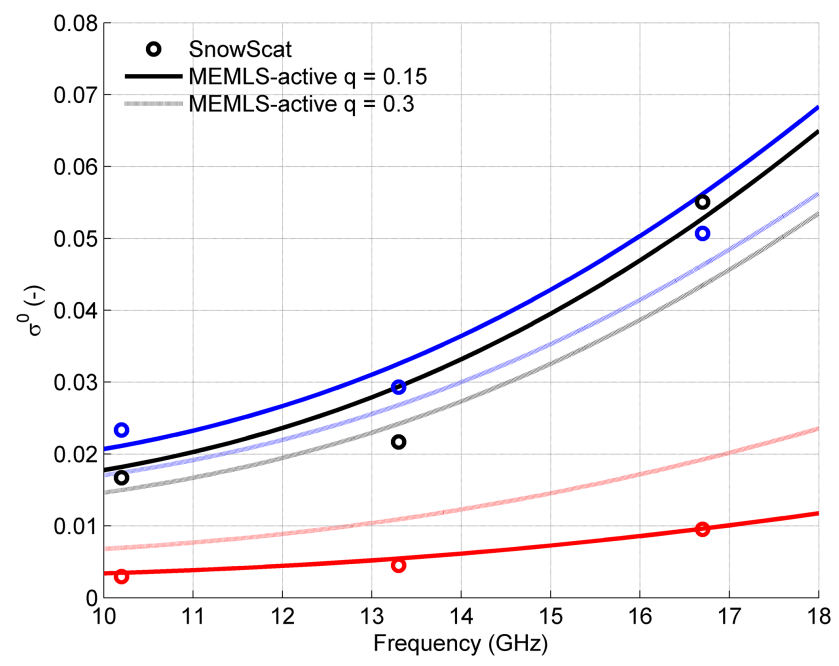

Figure 11. $\sigma^{0}$ at incidence angle $50^{\circ}$ measured by SnowScat (circles) and modeled by MEMLS3\&a with CT input (lines) for different cross-polarization ratios $q$. Higher $q$ ratios lead to lower $\sigma^{0}$ values for co-polarization and higher $\sigma^{0}$ values for cross-polarization. Colors represent polarization, with vv - black, hh - blue and hv red. Best fit parameters according to Fig. 7.

results of the 15 MEMLS runs in combination with the SodRad measurements.

The agreement between model and observation generally decreased towards higher frequencies. At $36 \mathrm{GHz}$ the average of all 15 MEMLS runs was at maximum $22 \mathrm{~K}$ too low for $\mathrm{v}$ pol and $12 \mathrm{~K}$ too low for h-pol. Compared to the operational azimuth angle of $190^{\circ}$, the difference between model and ob- 


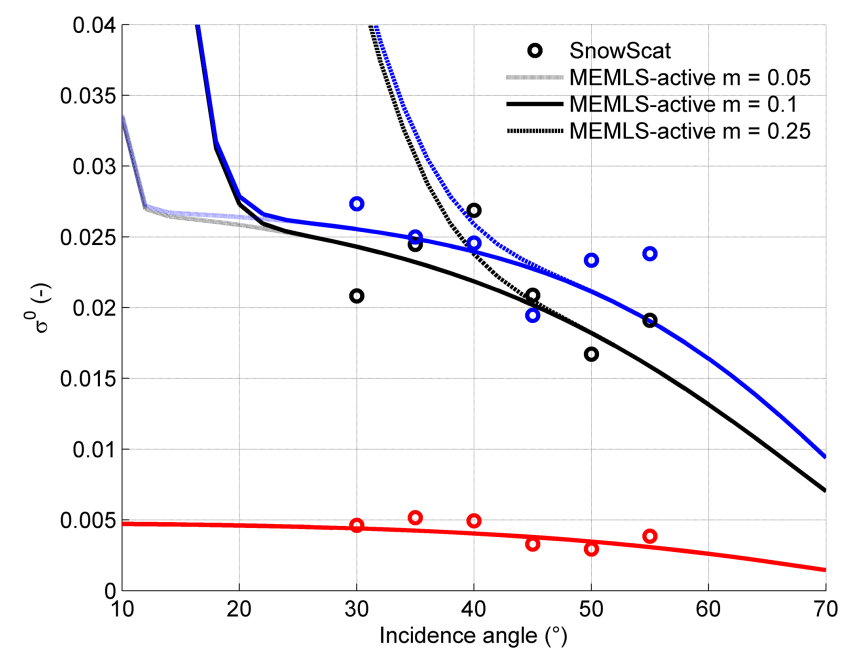

Figure 12. $\sigma^{0}$ measured by SnowScat (circles) and modeled by MEMLS3\&a with CT input (lines) at $10.65 \mathrm{GHz}$ for different mean slope of surface undulations $m$. Colors represent polarization, with $\mathrm{vv}$ - black, hh - blue and hv - red. Best fit parameters according to Fig. 7.

servation decreased to 16 and $1 \mathrm{~K}$ for v-pol and h-pol, respectively. The differences at $10 \mathrm{GHz}$ are comparably lower, with $5 \mathrm{~K}$ at maximum. The standard deviations of the 15 MEMLS runs, which are solely due to spatial variability of the snow, increased with frequency. At $36 \mathrm{GHz}$, the standard deviation was around $8 \mathrm{~K}$ for both polarizations. The difference in azimuth angles of SodRad was even larger, with $12 \mathrm{~K}$ at $36 \mathrm{GHz}$ h-pol. This underlines the influence of the spatial variability of the snowpack on modeled and measured brightness temperatures, which will be discussed in the next section. The agreement between model and observation should be always interpreted with respect to the variation in brightness temperatures caused by the spatial variability of the snowpack.

\section{Discussion}

As shown in Sect. 4, MEMLS3\&a simulations were in reasonable agreement with SnowScat observations. To achieve this agreement, however, several parameters were chosen to match model and observation. This was necessary, since the active part contains, in contrast to the passive part, empirical parameters $\left(s_{\mathrm{s} 0}, q\right.$ and $\left.m\right)$ which could not be measured. Likewise, the ground parameters $s_{0}$ and $\mathrm{rms}_{\mathrm{g}}$ are subject to uncertainties.

The specular part of the snow-ground reflectivity $s_{\mathrm{s} 0}$ was chosen to be proportional to $s_{0}$ and the same factor of 0.75 could be applied for all frequencies and polarizations to convert $s_{0}$ into $s_{\mathrm{s} 0}$. With $s_{\mathrm{S} 0}=0.75 s_{0}$, the main part of the snowground reflectivity is specular. This requires the ground to be smooth and the overlaying snow layer to be transparent. The vegetation is subject to very low temperatures and a steady

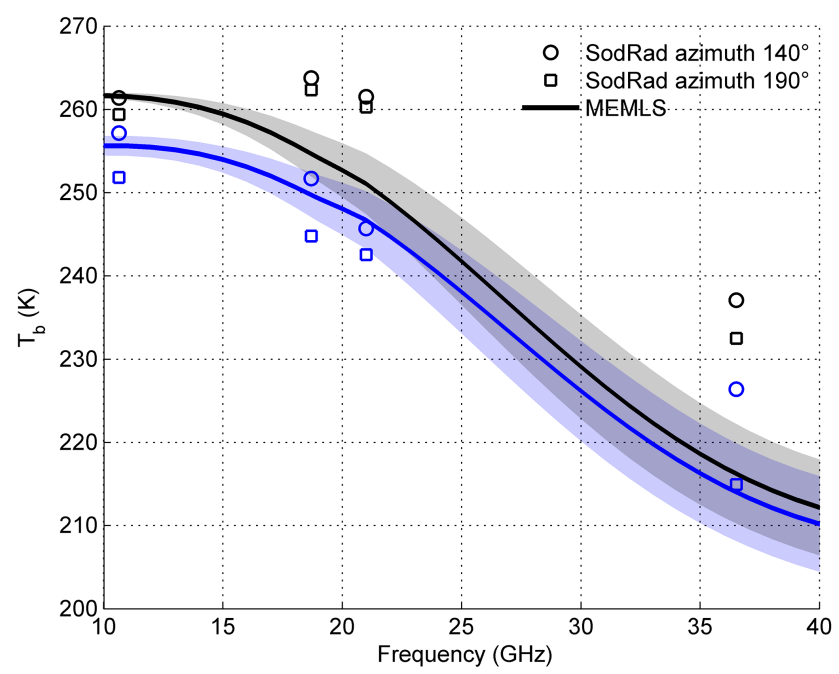

Figure 13. $T_{\mathrm{b}}$ measured by SodRad at an azimuth angles of $190^{\circ}$ (circles) and at $140^{\circ}$ (squares). $T_{\mathrm{b}}$ modeled by MEMLS from 15 SMP measurements, average (lines) with standard deviation (shaded). Colors represent polarization, with $\mathrm{v}-$ black and $\mathrm{h}-$ blue.

temperature gradient, which forces the water of the soft vegetation (lichen, mosses, shrubs (myrtillus species); Fig. 14) to move upwards into the snow. Given the height of the vegetation of less than $10 \mathrm{~cm}$, it seems reasonable to assume that the vegetation dries out during winter and can be treated as fully transparent for the present microwave frequencies. This allows the soil interface to act as specular reflector, which is then accounted for by $s_{\mathrm{s} 0}$ in the model. Though being reasonable, a sound justification of this line of argumentation requires further investigations.

The cross-polarization in MEMLS3\&a is solely determined empirically via the parameter $q$. This pragmatic approach was chosen since the physical origin of crosspolarization in snow is still the subject of ongoing research. In the DMRT based approach (Tsang et al., 2007), crosspolarization emerges from non-spherical shapes of aggregated sphere clusters. A different route to cross-polarization can be taken via the discrete dipole approximation (DDA), e.g., from Von Lerber et al. (2006) or Xu et al. (2012), which principally accounts for multiple reflections and polarizations inside a given snow volume. DDA requires the full three-dimensional description of the microstructure, which can be provided by $\mu \mathrm{CT}$. A comparison to such a model could further elucidate the justification and the value of the parameter $q$.

Another parameter chosen empirically is the mean slope of surface undulations $m$. In principle, this parameter could be obtained from the analysis of the surface height, similar to what has been done in Löwe et al. (2007) and Manes et al. (2008) for fresh snow. In a simple reasoning, the mean squared slope $m$ can be expressed as the ratio between the standard deviation of the surface height and the lateral cor- 


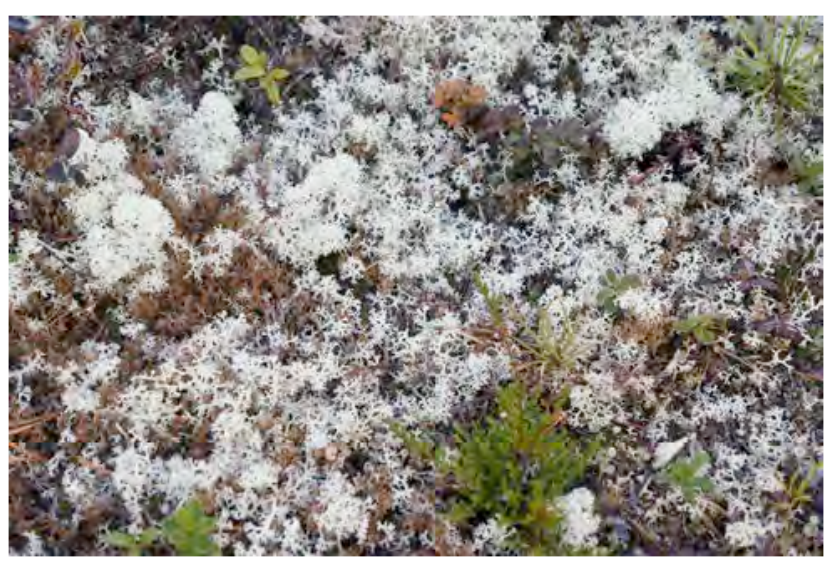

Figure 14. View of about $1 \mathrm{~m}^{2}$ of the snow-free surface at the radiometer test site in Sodankylä, Finland.

relation length of the height correlation function. According to Manes et al. (2008) $m$ would then take a value of 0.14 for fresh snow which is in the same order of magnitude as applied in our simulations $(m=0.1)$. This small-scale roughness of the snow surface is not taken into account by the model, where only slight surface undulations are allowed.

The individual magnitudes of the specular and diffuse contributions are shown in Fig. 15. Towards higher frequencies, the diffuse component increases and outweighs the specular reflectivity from $12.5 \mathrm{GHz}$ for $\mathrm{v}$-pol and from $14.5 \mathrm{GHz}$ for h-pol. Note that the magnitude of the specular component also depends on the undulation of the surface and therefore on the value of $m$. However, a pronounced impact of $m$ is limited to small incidence angles (Fig. 12 and Sect. 4.2.2) for reasonable values of $m(m \approx 0.1)$.

In contrast to MEMLS3\&a, MEMLS does not require free empirical parameters. In this regard, we attribute the fact that MEMLS3\&a matches the SnowScat observation better than MEMLS the SodRad observations to the additional free parameters in MEMLS3\&a, foremost $s_{\mathrm{s} 0}$ and $q$. However, for the passive simulations, parameters also had to be chosen without direct experimental justification, namely $s_{0}$ and $\mathrm{rms}_{\mathrm{g}}$, which determine the contribution of the snow-ground interface. This contribution is dominant and critical in our frequency range, as dry snowpacks thinner than $\sim 1 \mathrm{~m}$ are highly transparent. Unfortunately, the knowledge about the scattering at the ground surface is limited. Therefore, the snow-ground reflectivity $s_{0}$ was modeled using the model of Wegmüller and Mätzler (1999). This model is an empirical parametrization of the Fresnel formula depending on the standard deviation of the soil surface height $\mathrm{rms}_{\mathrm{g}}$ and the soil permittivities. For the soil permittivities, Hallikainen et al. (1985) provide experimental data and Mironov et al. (2010) an empirical model based on experimental data, but dielectric models for the permittivities of frozen soils are still under development. For $\mathrm{rms}_{\mathrm{g}}$ of the soil below the snowpack no measurements were available. In addition, the model of

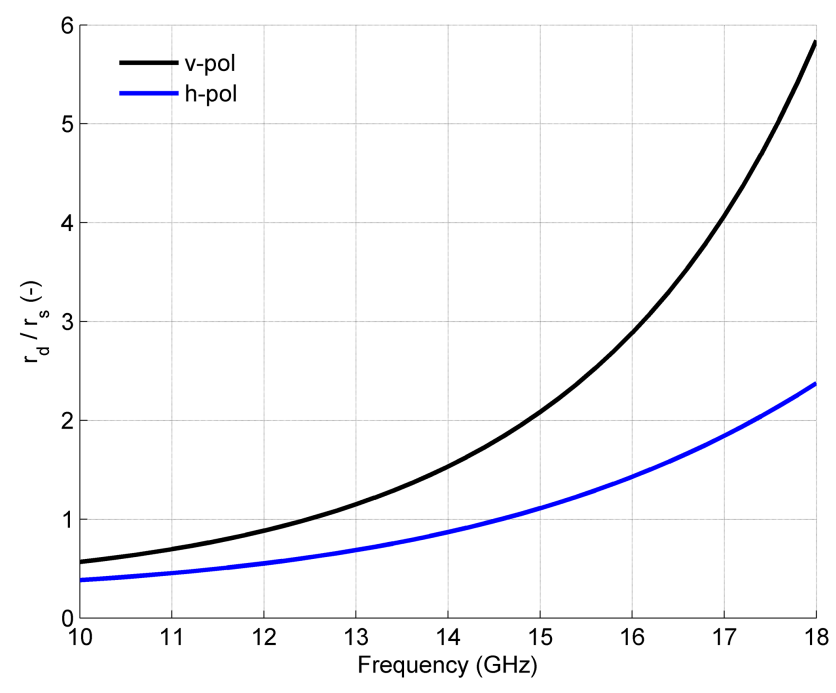

Figure 15. Ratio of the simulated diffuse $\left(r_{\mathrm{d}}\right)$ and specular $\left(r_{\mathrm{S}}\right)$ reflectivity at $50^{\circ}$ incidence angle per frequency, for the best fit parameters according to Fig. 7.

Wegmüller and Mätzler (1999) does not account for vegetation, which is in our case consistent with the argument on transparency given above. We note that estimating the snow-ground reflectivity is critical for all microwave models, which was also concluded from recent experiments (Roy et al., 2013; Montpetit et al., 2013). However, at $10 \mathrm{GHz}$, the frequency which is most influenced by the soil; MEMLS and SodRad were in good agreement.

In contrast, the mismatch between model and measurements was largest at $36 \mathrm{GHz}$ and is most sensitive to details of the snow microstructure. MEMLS assumes an exponential fit of the density correlation function of the snow microstructure. The exponential fit is a reasonable starting point but small deviations can have a large influence on scattering. As detailed by Löwe et al. (2011), the correlation function of snow can take different shapes and its representation by means of a single correlation length might be inappropriate. Instead the Teubner-Strey form, a two-scale form for bicontinuous media might be more appropriate. The inclusion of other types of correlation functions into MEMLS is possible by adapting the calculation of the scattering coefficient. We thus believe that the present model provides a suitable test case to investigate the impact of more sophisticated representations of the snow microstructure.

We further tried to assess the influence of the spatial variability of the snowpack. The standard deviation obtained from the 15 MEMLS runs is $8 \mathrm{~K}$ at $36.5 \mathrm{GHz}$, h- and v-pol, implying a non-negligible influence of the location of the in situ snow measurements on the modeled brightness temperatures.

We also found that the higher values measured by SodRad throughout the whole frequency range at h-pol for an azimuth angle of $140^{\circ}$ indicate an effect of the surrounding environ- 
ment, such as trees, which were closer to the field of view at this azimuth angle. The spatial variability of the snowpack together with the influence of the environment is potentially able to bias simulated and measured brightness temperatures.

The degree of complexity of existing models simulating microwave backscattering from snow range from singlelayer approaches (Rott et al., 2010) to numerical solutions of Maxwell's equations (Xu et al., 2012; Ding et al., 2010). In this context, we propose MEMLS3\&a as a model of intermediate complexity. In contrast to the HUT model (Pulliainen et al., 1999; Lemmetyinen et al., 2010), which has comparable complexity, MEMLS avoids traditional grain size as input parameter, which is prone to uncertainties in the visual estimation method (Painter et al., 2007). The advantage of MEMLS3\&a (as well as MEMLS) is the correlation length as microstructural quantity, which can be obtained from objective measurements without conversion and, given the SMP retrieval method, with high efficiency in the field.

Presently, models differ not only in the representation of snow microstructure but also in the solution of the radiative transfer or the type of interfaces between the layers, which makes it difficult to attribute the discrepancies in model performance to a particular part of the model. A comparison by Tedesco and Kim (2006) of at least the passive models showed that no model was able to reproduce all of the investigated microwave observations. For a detailed model assessment in view of future developments, various effects (spatial variability, snow microstructure, soil) must be isolated. A promising way is by using measurements of specifically prepared snow slabs, as already presented by Wiesmann et al. (1998). Together with complete 3-D microstructural information, these types of idealized experiments will allow us to minimize spatial variability, avoid the influence of the ground and compare different microstructural concepts for scattering coefficients. Together with available multi-layer models like MEMLS3\&a, DMRT-ML (Picard et al., 2013) or the DMRTQMS package (Chang et al., 2014), this will clarify our understanding of the processes involved in microwave emission and scattering of snow.

\section{Conclusions}

We adapted the MEMLS to include backscattering and presented a detailed description of the relevant parameters and their derivation. The reflectivity was decomposed into diffuse and specular components, and the snowpack was allowed to be slightly undulated. This procedure could be applied to other passive microwave models as well. Model simulations were in reasonable agreement with scatterometer observations, if the specular snow-ground reflectivity $s_{\mathrm{s} 0}$ and the cross-polarization ratio $q$ were chosen accordingly. We found that the contribution of the snow-ground interface is a critical parameter, which needs further investigation. The empirical formulation of the cross-polarization ratio $q$ is a limitation with respect to other existing microwave models. MEMLS3\&a is a model of intermediate complexity, which avoids fitting procedures of the scattering efficiency of snow in combination with SMP or $\mu \mathrm{CT}$ measurements. This eliminates a main uncertainty of snow characterization in microwave remote sensing.

MEMLS3\&a is integrated in the standard release of MEMLS as a separate sub-routine. Both versions, active and passive are built on the same set of core functions. 


\section{Appendix A: Specular reflectivity of the layered snowpack}

The purpose of the appendix is to derive the specular part of the reflectivity of a layered snowpack, in order to separate it from the diffuse part by subtraction from the total reflectivity using MEMLS. It is assumed here that all layer interfaces are smooth and parallel to the surface in order to produce specular reflection. Separation between diffuse and specular reflection is required in bistatic scattering and in backscatter models.

We consider a plane-parallel snowpack used in MEMLS as shown in Fig. 2. The relevant quantities of an arbitrary layer $j$ are shown in detail in Fig. A1. The layer is specified by a transmissivity $u_{j}$ for the directed radiation. The transmissivity is given by

$u_{j}=\exp \left(-\gamma_{\mathrm{e}, j} d_{j} / \cos \theta_{j-1}\right)$,

where $d_{j}=z_{j}-z_{j-1}$ is the thickness and $\gamma_{\mathrm{e}, j}$ is the extinction coefficient of layer $j$, respectively. In addition, the layer interfaces are characterized by an interface reflectivity, where $s_{j}$ denotes the reflectivity of the top interface of layer $j$. Assuming smooth interfaces, we can apply the Fresnel formulas to compute $s_{j}$. The propagation angle $\theta_{j-1}$ in layer $j$ is given by Snell's law of refraction. At the bottom of the snowpack, the reflectivity $s_{0}=s_{\mathrm{S} 0}+s_{\mathrm{d} 0}$ consists of a specular $s_{\mathrm{s} 0}$ and a diffuse $s_{\mathrm{d} 0}$ component.

The aim of the following procedure is to derive an expression for the total specular reflectivity, $R_{j}$, which results from transmission and reflections in all layers below $z_{j}$. In order to compute the specular reflectivity we assume sufficiently large directional intensities such that thermal radiation can be neglected. Note that $A_{j}, B_{j}, C_{j}$ and $D_{j}$ are downwelling and upwelling intensities just above and below the boundaries of the respective snow layer. By virtue of Fig. A1 we can derive the following equations relating the directional intensities at the boundaries:

$A_{j}=u_{j} C_{j}$,

$B_{j}=R_{j-1} A_{j}$,

$C_{j}=\left(1-s_{j}\right) A_{j+1}+s_{j} D_{j}$,

$D_{j}=u_{j} B_{j}$,

$B_{j+1}=R_{j} A_{j+1}=\left(1-s_{j}\right) D_{j}+s_{j} A_{j+1}$.

Furthermore, at the bottom we have

$R_{0}=s_{\mathrm{s} 0}$,

where $s_{\mathrm{s} 0}$ is the specular part of the ground-snow interface reflectivity.

In order to solve these equations for $R_{j}$, we first eliminate the $D_{j}$ and $C_{j}$ in Eqs. (A4) and (A6) by using Eqs. (A2) and (A5). In this way we obtain

$u_{j}\left(1-s_{j}\right) A_{j+1}=A_{j}-u_{j}^{2} s_{j} B_{j}$,

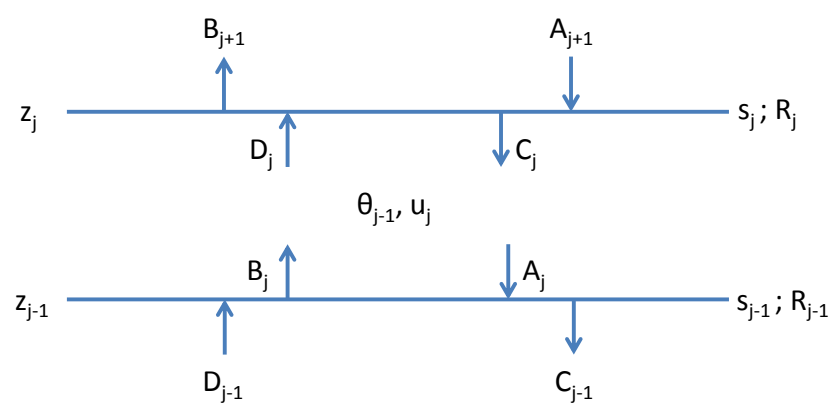

Figure A1. The parameters of a selected layer $j$ : height $z_{j}$, up- and downwelling intensities $A, B, C$, and $D$; transmissivity $u_{j}$ of directed radiation; refracted angle $\theta_{j-1}$; interface reflectivity $s_{j}$; and specular reflectivity $R_{j}$.

and

$B_{j+1}=\left(1-s_{j}\right) u_{j} B_{j}+s_{j} A_{j+1}$.

Dividing Eq. (A8) by $A_{j}$ and Eq. (A9) by $A_{j+1}$ we get, together with Eqs. (A6) and (A3),

$u_{j}\left(1-s_{j}\right) A_{j+1} / A_{j}=1-u_{j}^{2} s_{j} R_{j-1}$,

and

$R_{j}=\left(1-s_{j}\right) u_{j} R_{j-1} A_{j} / A_{j+1}+s_{j}$.

Eliminating the ratio $A_{j+1} / A_{j}=\left(1-u_{j}^{2} s_{j} R_{j-1}\right) /\left[u_{j}(1-\right.$ $\left.s_{j}\right)$ ] in Eq. (A11) leads to

$R_{j}=s_{j}+\left[\left(1-s_{j}\right) u_{j}\right]^{2} R_{j-1} /\left(1-u_{j}^{2} s_{j} R_{j-1}\right)$.

Equation (A12) is a recurrence relation for the total specular reflectivity at the snow surface, $r_{\mathrm{s}}=R_{n}$. The initial condition for the recurrence relation is given by the ground reflectivity in Eq. (A7).

The described procedure is applied for horizontal and vertical polarization, separately. For v polarization we call $R_{n}=$ $r_{\mathrm{s}, \mathrm{v}}$, and for h polarization we call $R_{n}=r_{\mathrm{s}, \mathrm{h}}$. These are the specular parts of the total reflectivities, $r_{\mathrm{v}}$ and $r_{\mathrm{h}}$ of MEMLS. The diffuse components $r_{\mathrm{d}, \mathrm{v}}$ and $r_{\mathrm{d}, \mathrm{h}}$ are thus

$r_{\mathrm{d}, \mathrm{v}}=r_{\mathrm{v}}-r_{\mathrm{s}, \mathrm{v}}$,

$r_{\mathrm{d}, \mathrm{h}}=r_{\mathrm{h}}-r_{\mathrm{s}, \mathrm{h}}$.

The diffuse components should be nearly the same at both polarizations. This property can be tested by computing $r_{\mathrm{d}, \mathrm{v}}$ and $r_{\mathrm{d}, \mathrm{h}}$ from Eqs. (10) and (13), taking the total reflectivities from MEMLS and the specular reflectivities from the method described here. 


\section{Code availability}

The model is written in Matlab and available to the public through the following website: http://www.iapmw.unibe.ch/ research/projects/snowtools/memls.html.

Acknowledgements. The validation data were acquired during Nordic Snow and Radar Experiment NoSREx III in Sodankylä, Finland, ESA ESTEC contract no. 22761/09/NL/JA. Proksch further acknowledges support from ESA's Networking/Partnering Initiative NPI no. 235-2012. In particular we want to acknowledge FMI staff for help and support during the field campaigns. A first version of this model is based on ESA ESTEC contract no. 4200020716/07/NL/EL CCN2.

Edited by: N. Kirchner

\section{References}

Arnaud, L., Picard, G., Champollion, N., Domine, F., Gallet, J. C., Lefebvre, E., Fily, M., and Barnola, J. M.: Measurement of vertical profiles of snow specific surface area with a $1 \mathrm{~cm}$ resolution using infrared reflectance: instrument description and validation, J. Glaciol., 57, 17-29, doi:10.3189/002214311795306664, 2011.

Chandrasekhar, S.: Radiative Transfer, Dover Publ., New York, NY, 1960.

Chang, W., Tan, S., Lemmetyinen, J., Tsang, L., Xu, X., and Yueh, S.: Dense media radiative transfer applied to SnowScat and SnowSAR, IEEE J. Sel. Top. Appl., 7, 3811-3825, doi:10.1109/JSTARS.2014.2343519, 2014.

Denoth, A., Foglar, A., Weiland, P., Mätzler, C., and Aebischer, H.: A comparative study of instruments for measuring the liquid water content of snow, J. Appl. Phys., 56, 2154-2160, doi:10.1063/1.334215, 1984.

Ding, K.-H., Xu, X., and Tsang, L.: Electromagnetic scattering by bicontinuous random microstructures with discrete permittivities, IEEE T. Geosci. Remote, 48, 3139-3151, 2010.

Durand, M., Kim, E., and Margulis, S. A.: Quantifying uncertainty in modeling snow microwave radiance for a mountain snowpack at the point-scale, including stratigraphic effects, IEEE T. Geosci. Remote, 46, 1753-1767, doi:10.1109/TGRS.2008.916221, 2008.

Fierz, C., Armstrong, R., Durand, Y., Etchevers, P., Greene, E., McClung, D., Nishimura, K., Satyawali, P., and Sokratov, S. A.: The international classification for seasonal snow on the ground, HPVII Technical Documents in Hydrology 83, IACS Contribution 1, UNESCO-IHP, Paris, 2009.

Gallet, J.-C., Domine, F., Zender, C. S., and Picard, G.: Measurement of the specific surface area of snow using infrared reflectance in an integrating sphere at 1310 and $1550 \mathrm{~nm}$, The Cryosphere, 3, 167-182, doi:10.5194/tc-3-167-2009, 2009.

Hallikainen, M., Ulaby, F., Dobson, M., El-Rayes, M., and Wu, L.: Microwave dielectric behavior of wet soil - Part 1: Empirical models and experimental observations, IEEE T. Geosci. Remote, 23, 25-34, 1985.

Heggli, M., Frei, E., and Schneebeli, M.: Instruments and methods snow replica method for three-dimensional $\mathrm{X}$ - ray microtomographic imaging, J. Glaciol., 55, 631-639, doi:10.3189/002214309789470932, 2009.

Kasten, F. and Raschke, E.: Reflection and transmission terminology by analogy with scattering, Appl. Optics, 13, 460-464, 1974.

Kokhanovsky, A.: Optics of Light Scattering Media, Problems and Solutions, 2nd Edn., Springer-Praxis, Chichester, UK, 2001.

Kong, J. A.: Electromagnetic Wave Theory, John Wiley, New York, 1986.

Kontu, A. and Pulliainen, J.: Simulation of spaceborne microwave radiometer measurements of snow cover using in situ data and brightness temperature modeling, IEEE T. Geosci. Remote, 48, 1031-1044, doi:10.1109/TGRS.2009.2030499, 2010.

Kontu, A., Lemmetyinen, J., Pulliainen, J., Seppänen, J., and Hallikainen, M.: Observation and modeling of the microwave brightness temperature of snow-covered frozen lakes and wetlands, IEEE T. Geosci. Remote, 52, 3275-3288, 2014.

Langlois, A., Royer, A., Derksen, C., Montpetit, B., Dupont, F., and Goïta, K.: Coupling the snow thermodynamic model SNOWPACK with the microwave emission model of layered snowpacks for subarctic and arctic snow water equivalent retrievals, Water Resour. Res., 48, W12524, doi:10.1029/2012WR012133, 2012.

Lemmetyinen, J., Pulliainen, J., Rees, A., Kontu, A., and Derksen, C.: Multiple-layer adaptation of HUT snow emission model: comparison with experimental data, IEEE T. Geosci. Remote, 48, 2781-2794, doi:10.1109/TGRS.2010.2041357, 2010.

Lemmetyinen, J., Kontu, A., Leppänen, L., Pulliainen, J., Wiesmann, A., Werner, C., Proksch, M., and Schneebeli, M.: Technical assistance for the development of an X-to Ku-Band Scatterometer during the NoSREx III experiment, Final report, ESA ESTEC Contract No. 22671/09/NL/JA, European Space Agency ESA ESTEC, Noordwijk, the Netherlands, 2013.

Lemmetyinen, J., Derksen, C., Toose, P., Proksch, M., Pulliainen, J., Kontu, A., Rautiainen, K., Seppänen, J., and Hallikainen, M.: Simulating seasonally and spatially varying snow cover brightness temperature using HUT snow emission model and retrieval of a microwave effective grain size, Remote Sens. Environ., 156, 71-95, 2015.

Löwe, H., Egli, L., Bartlett, S., Guala, M., and Manes, C.: On the evolution of the snow surface during snowfall, Geophys. Res. Lett., 34, L21507, doi:10.1029/2007GL031637, 2007.

Löwe, H., Spiegel, J. K., and Schneebeli, M.: Interfacial and structural relaxations of snow under isothermal conditions, J. Glaciol., 57, 499-510, doi:10.3189/002214311796905569, 2011.

Löwe, H., Riche, F., and Schneebeli, M.: A general treatment of snow microstructure exemplified by an improved relation for thermal conductivity, The Cryosphere, 7, 1473-1480, doi:10.5194/tc-7-1473-2013, 2013.

Manes, C., Guala, M., Löwe, H., Bartlett, S., Egli, L., and Lehning, M.: Statistical properties of fresh snow roughness, Water Resour. Res., 44, W11407, doi:10.1029/2007WR006689, 2008.

Matzl, M. and Schneebeli, M.: Measuring specific surface area of snow by near-infrared photography, J. Glaciol., 52, 558-564, doi:10.3189/172756506781828412, 2006.

Mätzler, C.: Applications of the interaction of microwaves with the seasonal snow cover, Remote Sens. Rev., 2, 259-387, 1987.

Mätzler, C.: Microwave Transmissivity of a Forest Canopy: Experiments Made with a Beech, Remote Sens. Environ., 48, 172-180, 1994. 
Mätzler, C.: Microwave permittivity of dry snow, IEEE T. Geosci. Remote, 34, 573-581, doi:10.1109/36.485133, 1996.

Mätzler, C.: Improved Born approximation for scattering of radiation in a granular medium, J. Appl. Phys., 83, 6111, doi:10.1063/1.367496, 1998.

Mätzler, C.: HPACK, a bistatic radiative transfer model for microwave emission and backscattering of snowpacks, and validation by surface-based experiments, Tech. Rep. IAP research report 2000-4, University of Bern, Switzerland, 2000.

Mätzler, C.: Relation between grain-size and correlation length of snow, J. Glaciol., 48, 461-466, 2002.

Mätzler, C.: On the determination of surface emissivity from Satellite observations, IEEE Geosci. Remote S., 2, 160-163, doi:10.1109/LGRS.2004.842448, 2005.

Mätzler, C. and Melsheimer, C.: Radiative transfer and microwave radiometry, in: Thermal Microwave Radiation - Applications for Remote Sensing, ET Electromagnetic Waves Series 52, 1-23, Institution of Engineering and Technology (IET), London, UK, 2006.

Mätzler, C. and Rosenkranz, P.: Dependence of microwave brightness temperature on bistatic surface scattering: model functions and application to AMSU-A, IEEE T. Geosci. Remote, 45, 2130 2138, 2007.

Mätzler, C. and Wiesmann, A.: Extension of the microwave emission model of layered snowpacks to coarse-grained snow, Remote Sens. Environ., 70, 317-325, doi:10.1016/S00344257(99)00047-4, 1999.

Mätzler, C. and Wiesmann, A.: Documentation for MEMLS, Version 3, Microwave Emission Model of Layered Snowpacks, Tech. rep., Institute for Applied Physics, University of Bern, Switzerland, 2012.

Mironov, V., DeRoo, R., and Savin, I.: Temperature-dependable microwave dielectric model for an Arctic soil, IEEE T. Geosci. Remote, 48, 2544-2556, 2010.

Montpetit, B., Royer, A., Roy, A., Langlois, A., and Derksen, C.: Snow microwave emission modeling of ice lenses within a snowpack using the microwave emission model for layered snowpacks, IEEE T. Geosci. Remote, 51, 4705-4717, doi:10.1109/TGRS.2013.2250509, 2013.

Painter, T., Molotch, N., Cassidy, M., Flanner, M., and Steffen, K.: Instruments and methods: contact spectroscopy for determination of stratigraphy of snow optical grain size, J. Glaciol., 53, 121-127, doi:10.3189/172756507781833947, 2007.

Picard, G., Brucker, L., Roy, A., Dupont, F., Fily, M., Royer, A., and Harlow, C.: Simulation of the microwave emission of multilayered snowpacks using the Dense Media Radiative transfer theory: the DMRT-ML model, Geosci. Model Dev., 6, 1061-1078, doi:10.5194/gmd-6-1061-2013, 2013.

Proksch, M. and Schneebeli, M.: Development of snow retrieval algorithms for $\mathrm{CoReH}_{2} \mathrm{O}$ grain size estimator: procedures for objective snow pack structure parameters, Tech. Rep. 22830/09/NL/JC, European Space Agency, Noordwijk, the Netherlands, 2012.

Proksch, M., Löwe, H., and Schneebeli, M.: Density, specific surface area and correlation length of snow measured by high-resolution penetrometry, J. Geophys. Res., 120, 346-362, doi:10.1002/2014JF003266, 2015.

Pulliainen, J., Grandell, J., and Hallikainen, M.: HUT snow emission model and its applicability to snow water equiv- alent retrieval, IEEE T. Geosci. Remote, 37, 1378-1390, doi:10.1109/36.763302, 1999.

Rautiainen, K., Lemmetyinen, J., Pulliainen, J., Vehviläinen, Drusch, M., Kontu, A., Kainulainen, J., and Seppänen, J.: L-band radiometer observations of soil processes in boreal and subarctic environments, IEEE T. Geosci. Remote, 50, 1483-1497, doi:10.1109/TGRS.2011.2167755, 2012.

Rees, A., Lemmetyinen, J., Derksen, C., Pulliainen, J., and English, M.: Observed and modelled effects of ice lens formation on passive microwave brightness temperatures over snow covered tundra, Remote Sens. Environ., 114, 116-126, doi:10.1016/j.rse.2009.08.013, 2010.

Rott, H., Yueh, S., Cline, D., and Duguay, C.: Cold regions hydrology high-resolution observatory for snow and cold land processes, P. IEEE, 98, 752-765, doi:10.1109/JPROC.2009.2038947, 2010.

Roy, A., Picard, G., Royer, A., Montpetit, B., Dupont, F., Langlois, A., Derksen, C., and Champollion, N.: Brightness temperature simulations of the Canadian seasonal snowpack driven by measurements of snow specific surface area, IEEE T. Geosci. Remote, 51, 4692-4704, doi:10.1109/TGRS.2012.2235842, 2013.

Schneebeli, M. and Johnson, J.: A constant-speed penetrometer for high-resolution snow stratigraphy, Ann. Glaciol., 26, 107-111, 1998.

Schneebeli, M. and Sokratov, S.: Tomography of temperature gradient metamorphism of snow and associated changes in heat conductivity, Hydrol. Processes, 18, 3655-3665, doi:10.1002/hyp.5800, 2004.

Schwank, M., Rautiainen, K., Mätzler, C., Stähli, M., Lemmetyinen, J., Pulliainen, J., Vehviläinen, J., Kontu, A., Ikonen, J., Ménard, C. B., Drusch, M., Wiesmann, A., and Wegmüller, U.: Model for microwave emission of a snow-covered ground with focus on L band, Remote Sens. Environ., 154, 180-191, doi:10.1016/j.rse.2014.08.029, 2014.

Takala, M., Luojus, K., Pulliainen, J., Derksen, C., Lemmetyinen, J., Kämä, Koskinen, J., and Bojkov, B.: Estimating northern hemisphere snow water equivalent for climate research through assimilation of space-borne radiometer data and groundbased measurements, Remote Sens. Environ., 115, 3517-3529, doi:10.1016/j.rse.2011.08.014, 2011.

Tan, S., Chang, W., Tsang, L., Lemmetyinen, J., and Proksch, M.: Modeling both active and passive microwave remote sensing of snow using dense media radiative transfer (DMRT) theory with multiple scattering and backscattering enhancement, IEEE J. Sel. Top. Appl., in press, 2015.

Tedesco, M. and Kim, E.: Intercomparison of electromagnetic models for passive microwave remote sensing of snow, IEEE T. Geosci. Remote, 44, 2654-2666, 2006.

Toure, A. M., Goïta, K., Royer, A., Kim, E. J., Durand, M., Margulis, S. A., and Lu, H.: A case study of using a multilayered thermodynamical snow model for radiance assimilation, IEEE T. Geosci. Remote, 48, 2828-2837, 2011.

Tsang, L., Blanchard, A., Newton, R., and Kong, J. A.: A simple relation between active and passive microwave remote sensing measurements of earth terrain, IEEE T. Geosci. Remote, 20, 482485, 1982.

Tsang, L., Pan, J., Liang, D., Li, Z., Cline, D., and Tan, Y.: Modeling active microwave remote sensing of snow using dense media ra- 
diative transfer (DMRT) theory with multiple-scattering effects, IEEE T. Geosci. Remote, 45, 990-1004, 2007.

Ulaby, F., Moore, R., and Fung, A.: Microwave Remote Sensing Active and Passive, Vol. I, Microwave Remote Sensing Fundamentals and Radiometry, Addison-Wesley Publishing Company, Reading, Mass., USA, 1981.

Ulaby, F., Moore, R., and Fung, A.: Microwave Remote Sensing Active and Passive, Vol. II, Radar Remote Sensing and Surface Scattering and Emission Theory, Addison-Wesley Publishing Company, Reading, Mass., USA, 1982.

Ulaby, F., Stiles, W., and Abdelrazik, M.: Snow cover influence on backscattering from terrain, IEEE T. Geosci. Remote, 22, 126133, 1984.

Von Lerber, A., Sarvas, J., and Pulliainen, J.: Modeling snow volume backscatter combining the radiative transfer theory and the discrete dipole approximation, in: IEEE International Conference on Geoscience and Remote Sensing, Symposium, 31 July-4 August 2006, Denver, CO, USA, 481-484, doi:10.1109/IGARSS.2006.128, 2006.

Wegmüller, U. and Mätzler, C.: Rough bare soil reflectivity model, IEEE T. Geosci. Remote, 37, 1391-1395, 1999.

Weise, T.: Radiometric and Structural Measurements of Snow, PhD thesis, Institute of Applied Physics, University of Bern, Switzerland, 1996.
Werner, C., Wiesmann, A., Strozzi, T., Schneebeli, M., and Mätzler, C.: The snowscat ground-based polarimetric scatterometer: calibration and initial measurements from Davos Switzerland, in: IEEE International Geoscience and Remote Sensing Symposium (IGARSS), 25-30 July 2010, Honolulu, HI, USA, 2363-2366, 2010.

Wiesmann, A.: Catalog of Radiometric and Structural snow sample measurements, Tech. Rep. IAP research report 97-1, University of Bern, Switzerland, 1997.

Wiesmann, A. and Mätzler, C.: Microwave emission model of layered snowpacks, Remote Sens. Environ., 70, 307-316, doi:10.1016/S0034-4257(99)00046-2, 1999.

Wiesmann, A., Mätzler, C., and Weise, T.: Radiometric and structural measurements of snow samples, Radio Sci., 33, 273-289, 1998.

Xu, X., Tsang, L., and Yueh, S.: Electromagnetic models of co/cross polarization of bicontinuous/DMRT in radar remote sensing of terrestrial snow at X- and $\mathrm{Ku}$-band for $\mathrm{CoReH}_{2} \mathrm{O}$ and SCLP applications, IEEE J. Sel. Top. Appl., 5, 1024-1032, 2012. 